\title{
Construction, Growth, and Harvesting of Fission Yeast Stable Isotope Labeling by Amino Acids in Cell Culture (SILAC) Strains
}

\author{
André Koch,, 1,4 Claudia C. Bicho, 2,5 Weronika E. Borek, ${ }^{2}$ Alejandro Carpy, ${ }^{3}$ Boris Maček, ${ }^{3,7}$ Silke Hauf, 1,6 \\ and Kenneth E. Sawin'2,7 \\ ${ }^{1}$ Friedrich Miescher Laboratory of the Max Planck Society, Tuebingen 72076, Germany; ${ }^{2}$ Wellcome Trust Centre \\ for Cell Biology, School of Biological Sciences, University of Edinburgh, Edinburgh EH9 3BF, United Kingdom; \\ ${ }^{3}$ Proteome Center Tuebingen, Interfaculty Institute for Cell Biology, University of Tuebingen, 72076 Tuebingen, \\ Germany
}

Stable isotope labeling by amino acids in cell culture (SILAC) enables the relative quantification of protein amounts and posttranslational modifications in complex biological samples through the use of stable heavy isotope-labeled amino acids. Here we describe methods for the application of SILAC to fission yeast Schizosaccharomyces pombe using either labeled lysine or a combination of labeled lysine and labeled arginine. The latter approach is more complicated than the use of labeled lysine alone but may yield a more comprehensive (phospho)proteomic analysis. The protocol includes methods for construction of SILAC-compatible strains, growth of cultures in labeled medium, cell harvesting, and protein extraction.

It is essential that you consult the appropriate Material Safety Data Sheets and your institution's Environmental Health and Safety Office for proper handling of equipment and hazardous material used in this protocol.

RECIPES: Please see the end of this protocol for recipes indicated by $<R>$. Additional recipes can be found online at http://cshprotocols.cshlp.org/site/recipes.

EMM2 $<\mathrm{R}>$ with appropriate supplements (plates containing solid medium)

EMM2-LowAmm $<\mathrm{R}>$ (liquid medium)

EMM2-LowAmm (low ammonium) is prepared in the same way as EMM2, but contains 6 mм ammonium chloride $(0.32 \mathrm{~g} / \mathrm{L})$ instead of the normal $93.5 \mathrm{~mm}(5 \mathrm{~g} / \mathrm{L})$.

\footnotetext{
${ }^{4}$ Present address: Department of Cell Biology, The Netherlands Cancer Institute, 1066 CX Amsterdam, The Netherlands

${ }^{5}$ Present address: Department of Cell and Tissue Biology, University of California San Francisco, San Francisco, California 94143

${ }^{6}$ Present address: Department of Biological Sciences and Virginia Bioinformatics Institute, Virginia Tech, Blacksburg, Virginia 24061

${ }^{7}$ Correspondence: boris.macek@uni-tuebingen.de; ken.sawin@ed.ac.uk

From the Fission Yeast collection, edited by lain M. Hagan, Antony M. Carr, Agnes Grallert, and Paul Nurse.

(C) 2017 Cold Spring Harbor Laboratory Press

Cite this protocol as Cold Spring Harb Protoc; doi:10.1101/pdb.prot091678
} 
A. Koch et al.

Oligonucleotide primers for yeast colony polymerase chain reaction (PCR) as described in Protocol: Colony Polymerase Chain Reaction with Schizosaccharomyces pombe (Murray et al. 2016)

aru $1 \Delta$ reverse primer: 5'-GTTGGAGTCGTATCCTCCGTTG-3'

car $1 \Delta$ reverse primer: $5^{\prime}$-CAATTCAATTCATGTGAAAAAG-3'

car $2 \Delta$ reverse primer: $5^{\prime}$-CCAAAATTTTTTATTTTAAC- $3^{\prime}$

kanMX forward primer: 5'-GGTTGCATTCGATTCCTGTTTGTAATTG-3'

These primers are used to verify gene deletions relating to arginine catabolism. The same forward primer is used for all three deletions, whereas each deletion requires a unique reverse primer. Primers are not needed

if labeling is to be done only with lysine and the lys 1-131 or lys3-37 mutant.

Protein assay reagents

Stable isotope labeling by amino acids in cell culture (SILAC) amino acids $<\mathrm{R}>$ (see Discussion)

Prepare two or more of the following according to the provided recipe.

L-lysine-2 $\mathrm{HCl}$ ("light" lysine)

L-Lysine-4,4,5,5-d4·HCl ("heavy" lysine; lysine-4)

$\mathrm{L}-\left[{ }^{13} \mathrm{C}_{6}\right]$ lysine $2 \mathrm{HCl}$ ("heavy" lysine; lysine-6)

$\mathrm{L}-\left[{ }^{13} \mathrm{C}_{6}^{15} \mathrm{~N}_{2}\right]$ lysine $\cdot \mathrm{HCl}$ ("heavy" lysine; lysine-8)

$\mathrm{L}$-arginine· $\mathrm{HCl}$ ("light” arginine)

$\mathrm{L}-\left[{ }^{13} \mathrm{C}_{6}\right]$ arginine $\cdot \mathrm{HCl}$ ("heavy" arginine; arginine-6)

Heavy isotope-labeled amino acids are available from Sigma-Aldrich (Isotec), Silantes, and Cambridge Isotopes (various distributors worldwide). Prices vary, and delivery times can sometimes be several weeks, so obtain prices from several suppliers and order well in advance of experiments. Because of bulk pricing, it is useful to buy reagents for multiple experiments at once.

Light and heavy arginines are not needed if labeling is to be done only with lysine. The decision about which version(s) of heavy lysine to use depends on the experiment. In double SILAC experiments (i.e., using two different isotopes), typical combinations are light lysine and either lysine-6 or lysine-8; in triple SILAC experiments, a combination of light lysine with lysine-4 and lysine-8 is preferred. In general, a mass difference between the labeled amino acids of 3 Da or higher will greatly facilitate quantification.

Yeast extract with supplements (YES) $<\mathrm{R}>$ (plates containing solid medium)

If desired, add $200 \mathrm{mg} / \mathrm{L}$ arginine to improve growth of arginine auxotrophic strains (see Step 2).

If required, add $133 \mu \mathrm{g} / \mathrm{mL}$ of G418 to select for kanMX6.

Yeast strains of interest, plus reagents for construction of the following mutant strains

lys1-131 or lys3-37

$\operatorname{arg1-230~(for~heavy~arginine~labeling)~}$

car2 $\Delta:: k a n M X$, or aru1 $\Delta:: k a n M X$ and car $1 \Delta:: k a n M X$ (for heavy arginine labeling; see Discussion)

Equipment

Ball mill (Mixer Mill MM400 [Retsch] or similar)

Ball mill buckets (e.g., 50-mL) with metal ball (25-mm-diameter])

Centrifuge

Centrifuge tubes (50-mL, screw-cap)

Cryotubes or Falcon tubes

Flasks

For all culture steps, use a flask that holds at least 10 times the amount of culture volume (i.e., a 100-mL flask for a $10-m L$ culture). We prefer baffled flasks.

Grinding jar tongs

Liquid nitrogen $\left(\mathrm{LN}_{2}\right)$ in an insulated container

In addition, prepare a small ice bucket containing $L N_{2}$ for Step 19.

Pipette tips (1000-mL)

Cut off $0.2 \mathrm{~cm}$ from the tip ends for pipetting cells in Step 19 .

Shaking incubator $(\geq 200 \mathrm{rpm})$ 
Sieve

Spatula or laboratory spoon

\section{METHOD}

\section{Constructing Strains for SILAC}

If using heavy lysine only (and not heavy arginine), parts of the protocol can be ignored as indicated.

1. Introduce the following mutations into the yeast strains of interest to be compared.

- lys1-131 or lys3-37

- $\arg 1-230$

- either car2 $\Delta:: k a n M X$, or car $1 \Delta:: k a n M X$ and aru1 $1:: k a n M X$ (see Discussion)

In addition, cross out any other auxotrophic markers.

For heavy lysine labeling, either the lys1-131 or the lys3-37 mutation must be introduced; the other mutations are relevant only when heavy arginine is used.

We have not determined the importance of crossing out other auxotrophic markers, but we routinely do this to minimize unknown factors that could potentially affect labeling and/or robust cell growth.

2. Germinate spores on plates containing YES solid medium.

Lysine-auxotrophic strains grow well on YES, whereas arg1-230 mutants sometimes grow slowly on YES, depending on the commercial source of the yeast extract. If in doubt, YES plates supplemented with $200 \mathrm{mg} / \mathrm{L}$ of arginine hydrochloride should be used.

3. Check lysine and arginine auxotrophies independently by replica-plating on plates containing EMM2 solid medium with appropriate supplements.

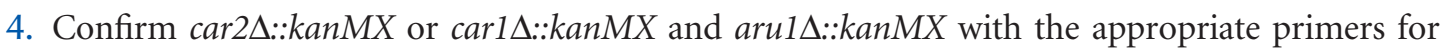
yeast colony PCR as described in Protocol: Colony Polymerase Chain Reaction with Schizosaccharomyces pombe (Murray et al. 2016).

If multiple kanMX markers are present in a cross, gene conversion events can eliminate one kanMX allele. This is an important consideration when tetrad dissection is used for strain construction, because it will not always be sufficient to identify double mutants on the basis of nonparental ditype tetrads; this also applies to natMX or hphMX markers.

5. Freeze the validated autotrophic strain using standard methods (see Introduction: Growth and the Environment of Schizosaccharomyces pombe [Petersen and Russell 2016]). Store until ready to proceed with Step 6.

Growing Strains for SILAC

Day 0

6. Thaw the auxotrophic S. pombe strain on a plate containing YES solid medium with appropriate antibiotics. Incubate at the appropriate temperature overnight.

\section{Day 1}

7. Harvest a few cells from the plate with a pipette tip and resuspend them in $100 \mu \mathrm{L}$ of EMM2LowAmm.

8. Add the cell solution to a flask containing $10 \mathrm{~mL}$ of EMM2-LowAmm supplied with light $\mathrm{L}$-lysine and, if required, light L-arginine. Grow the cells overnight with shaking at $\geq 200 \mathrm{rpm}$.

The final concentration of amino acids in the medium should be $200 \mathrm{mg} / \mathrm{L}$ of lysine for labeling with lysine alone, or $60 \mathrm{mg} / \mathrm{L}$ of lysine and $80 \mathrm{mg} / \mathrm{L}$ of arginine for double labeling. Concentrations of $30 \mathrm{mg} / \mathrm{L}$ lysine and $40 \mathrm{mg} / \mathrm{L}$ arginine were used originally (Bicho et al. 2010) but result in an approximately twofold lower growth yield (measured by optical density at $595 \mathrm{~nm}$ during the stationary phase) and thus require larger culture volumes. Concentrations of lysine and arginine higher than the "60/80" formulation do not proportionally increase yields and are therefore less cost-effective. 
A. Koch et al.

Day 2

9. Pellet the culture and wash twice with $10 \mathrm{~mL}$ of EMM2-LowAmm (without L-lysine or L-arginine) to remove residual L-lysine (and L-arginine). Resuspend the cells in EMM2-LowAmm and determine cell concentration.

10. Inoculate a flask containing $10 \mathrm{~mL}$ of EMM2-LowAmm supplemented with light or heavy Llysine and/or L-arginine using the same amino acid concentrations as in Step 8. Grow the cells for three to four cell doublings, such that cells are maintained in log-phase growth throughout culture (i.e., not exceeding $\sim 1-1.5 \times 10^{7}$ cells $/ \mathrm{mL}$ ).

11. From the culture in Step 10, inoculate a flask containing the desired culture volume of prewarmed EMM2-LowAmm supplemented with light or heavy L-lysine and/or L-arginine. Grow the cells to reach another four to six cell doublings.

In principle, growth in heavy medium for seven to eight generations should be sufficient to decrease the pool of light amino acids by at least $99 \%$ (e.g., $>200$-fold if 8 generations $=1 / 2^{8}$ ). In practice, a few more generations of growth may be beneficial. Growing the labeled cultures in two stages ensures that the larger-volume culture is inoculated under optimal growth conditions. This can prevent problems if the strain being used does not grow well at very low cell densities.

12. Proceed to cell harvesting.

Cells should be harvested at a density no $>2.4 \times 10^{7}$ cells $/ \mathrm{mL}$. This density (late log phase) is higher than that typically used for conventional biochemical experiments and is motivated by the high cost of heavy-labeled amino acids. For some experiments, lower densities may be more appropriate. Cells grown in light medium should always be grown to the same density as cells grown in heavy medium. Cells grown in $30 \mathrm{mg} / \mathrm{L}$ of lysine and $40 \mathrm{mg} / \mathrm{L}$ of arginine should be harvested at a lower density of $1.2 \times 10^{7}$ cells $/ \mathrm{mL}$, because they reach the stationary phase at lower cell densities.

Harvesting Cells

The following steps can be performed at room temperature or in a cold room at $4^{\circ} \mathrm{C}$, according to experimental needs. All reagents and materials (such as $\mathrm{dd}_{2} \mathrm{O}$, centrifuge tubes, pipette tips, buckets, centrifuge, etc.) should be brought to the appropriate temperature before proceeding.

Methods other than centrifugation for harvesting cells (e.g., filtration) can be used depending on culture volume.

The highly viscous culture suspension required for dropping cells into $L N_{2}$ (Step 19) can be obtained easily in the conical bottom of a 50-mL screw-cap centrifuge tube; thus, we highly recommend switching to these tubes during the washing steps (Steps 15-18).

13. Count the cells to determine the volume of each sample that will later be required for mixing samples from different conditions at a 1:1(:1) ratio.

Mixing of samples from different conditions can be performed just before or just after protein extraction (see below).

14. Harvest the cells by centrifugation for $3-5 \mathrm{~min}$ at $3000 \mathrm{~g}$.

15. Decant the culture medium and wash the cells with $\mathrm{ddH}_{2} \mathrm{O}$ to remove residual medium.

High salt concentration from residual medium may interfere with sample preparation (strong cation exchange [SCX] chromatography) for subsequent mass spectrometry.

16. Harvest the cells by centrifugation for 3-5 min at $3000 \mathrm{~g}$.

17. Wash twice more with $\mathrm{ddH}_{2} \mathrm{O}$ as in Steps 15-16.

18. Decant the supernatant of the last washing step and resuspend the cell pellet in the residual liquid in the tube.

If needed, a very small volume of $d \mathrm{dH}_{2} \mathrm{O}$ can be added to allow pipetting of the cells in the next step.

19. Take up the cell suspension with a $1000-\mu \mathrm{L}$ pipette, using a tip with $0.2 \mathrm{~cm}$ removed. Do not take up more than $500 \mu \mathrm{L}$ at once. Slowly, add cells dropwise to $\mathrm{LN}_{2}$ in an ice bucket (Fig. 1A).

20. Recover the cell droplets by decanting the $\mathrm{LN}_{2}$ through a sieve. Transfer the droplets to a $50-\mathrm{mL}$ screw-cap tube precooled in $\mathrm{LN}_{2}$. Store the cell droplets at $-80^{\circ} \mathrm{C}$ as needed. 

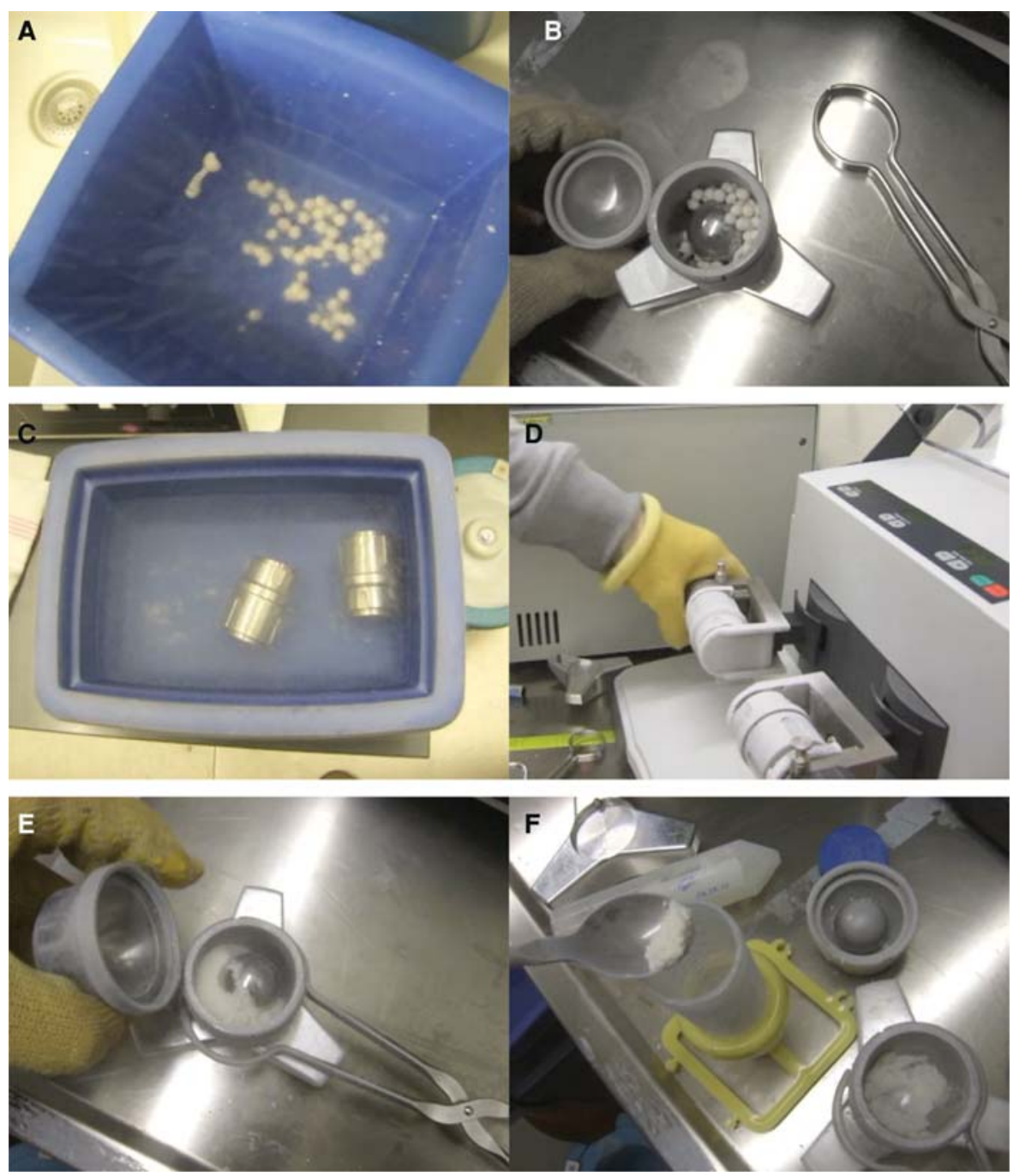

FIGURE 1. Preparation of protein extracts using a ball mill. (A) Cell suspension is dropped into liquid nitrogen. (B) Frozen cell droplets are transferred into a metal bucket (precooled in $\mathrm{LN}_{2}$ ) that contains a metal ball to disrupt cells. $(C)$ The bucket with cells is closed and again cooled in $\mathrm{LN}_{2}$. (D) Cells within the bucket are placed into a ball mill and disrupted by rapid shaking of the bucket containing the metal ball. $(E)$ Cell powder is obtained. $(F)$ Cell powder is transferred to a tube for additional storage or further processing.

Extracting Protein

The few residual cells remaining in the tube can be used for additional analyses, such as methanol/ethanol fixation and microscopy; see Protocol: Immunofluorescence Microscopy of Schizosaccharomyces pombe Using Chemical Fixation (Hagan 2016).

Cell disruption should be performed under cryogenic conditions. Here we explain protein extraction using a ball mill grinder (Fig. 1; see online Movie 1 at cshprotocols.cshlp.org). The ball mill is easy to handle and makes it easy to maintain cryogenic conditions. However, any other method that efficiently lyses S. pombe cells without impairing protein integrity should work as well; see Protocol: Large-Scale Immunoprecipitation from Fission Yeast Cell Extracts (Grallert and Hagan 2016).

We typically mix the cell droplets of the different conditions 1:1(:1) (judged by cell number) before protein extraction to minimize differences in sample preparation. Alternatively, cells can be lysed first, and the protein concentration determined before mixing $1: 1(: 1)$.

We perform all of the following steps in a cold room. (Note that use of $L_{2}$ in a closed room carries the risk of asphyxiation.) Precool all materials that come in direct contact with the cell droplets or the cell powder (ball mill bucket and ball, laboratory spoons, cryotubes or Falcon tubes, etc.) in $\mathrm{LN}_{2}$.

21. Fill the cell droplets into the precooled ball mill bucket, include an appropriately sized ball, and close the bucket. Cool again before the first ball mill run (Fig. 1B,C). 
22. Fix the bucket in the ball mill and run 3 min with 30 shakes/sec (Fig. 1D).

23. Remove the bucket and use precooled tongs to place in $\mathrm{LN}_{2}$ in an insulated container until full cooling is achieved.

24. Repeat the ball mill run (Steps 22 and 23) two to three times.

25. Open the bucket and quickly transfer the cell powder to precooled cryotubes or Falcon tubes using a precooled laboratory spoon (Fig. 1E,F).

If this step takes too long, humidity from the air will freeze on the inside of the bucket and the cell powder will start to accumulate additional water in the form of ice, which reduces the overall protein concentration per volume. If the spoon used for transfer is too warm, the cell powder will melt and be difficult to transfer.

26. Take a small sample of cell powder to determine the protein concentration. Store the cell powder at $-80^{\circ} \mathrm{C}$ until analysis (see Protocol: Stable Isotope Labeling by Amino Acids in Cell Culture (SILAC)-Based Quantitative Proteomics and Phosphoproteomics in Fission Yeast [Carpy et al. 2016]).

One of the more salient technical issues associated with SILAC in S. pombe involves the use of heavylabeled arginine. A key feature of the arginine-labeling protocol above is the use of a deletion mutant of predicted arginases $c a r 1^{+}$and $a r u 1^{+}$, or of predicted ornithine transaminase $c a r 2^{+}$, to minimize catabolic conversion of labeled arginine to other amino acids. This protocol was originally developed and validated for use with ${ }^{13} \mathrm{C}_{6}$-arginine (arginine-6), and ${ }^{13} \mathrm{C}_{6}$-lysine (lysine-6) (Bicho et al. 2010). Recently, 4,4,5,5- $\mathrm{d}_{4}$-lysine (lysine-4), ${ }^{13} \mathrm{C}_{6},{ }^{15} \mathrm{~N}_{2}$-lysine (lysine-8), and ${ }^{13} \mathrm{C}_{6},{ }^{15} \mathrm{~N}_{4}$-arginine (arginine10) have become more widely available. In our laboratory, we have encountered problems when the protocol is followed using arginine-10 rather than arginine-6; these are caused by degradation of the guanidinium group of ${ }^{13} \mathrm{C}_{6}^{15} \mathrm{~N}_{4}$-arginine to ${ }^{15} \mathrm{~N}_{1}$-ammonia, which is then used as a precursor in amino acid biosynthesis. We have independently developed two possible strategies to address this issue. First, a reduction of the urease activity by inactivation of the $\mathrm{Ni}^{2+}$ transporter Nicl enables full incorporation of ${ }^{13} \mathrm{C}_{6}^{15} \mathrm{~N}_{4}$-arginine and compatibility of fission yeast with SILAC (Carpy et al. 2015). Alternatively, specific use of car $1 \Delta$ aru $1 \Delta$ double mutants instead of car $2 \Delta$ single mutants for the inhibition of arginine conversion also addresses the problem (Borek et al. 2015). At present, for S. pombe strains described in this protocol, we strongly recommend the use of arginine- 6 in experiments. We have not encountered comparable problems when lysine- 8 is used in place of lysine- 6 , and thus lysine- 6 and lysine- 8 can be considered largely interchangeable. Lysine- 4 is particularly useful for triple SILAC experiments (comparing three conditions), where it can be combined with unlabeled lysine and lysine- 8 .

When arg1-230 lys3-37 cells are grown in conventional EMM2 containing arginine and lysine as supplements, inoculation of growing cultures into fresh medium at high dilution (i.e., low cell density) results in an extremely long lag phase (2-3 d!) before normal growth (Bicho et al. 2010). However, immediate robust growth upon dilution can be achieved simply by decreasing the concentration of ammonium chloride in the growth medium, from $96 \mathrm{~mm}$ (normal) to $\sim 6-24 \mathrm{~mm}$ (Bicho et al. 2010). Remarkably, even at $6 \mathrm{~mm}$ ammonium chloride, good growth immediately ensues, indicating that normal formulations of EMM2 contain far more nitrogen source than is actually required for growth. The reason why growth of arg1-230 lys3-37 mutants is improved by decreasing the ammonium chloride concentration has not been investigated in great detail, but there is evidence for two types of arginine permeases in fission yeast, one of which is competitively inhibited by basic amino acids (e.g., lysine), and the other of which is inhibited by ammonium ions (Fantes and Creanor 1984). Therefore, the decrease in ammonium chloride concentration likely allows successful uptake of exogenous arginine by one arginine permease in the face of lysine-dependent inhibition of the other arginine permease. Excellent results can also be obtained using EMMG, which contains 20-22 mM Lglutamic acid instead of ammonium chloride (Carpy et al. 2015); see Introduction: Growth and the 
Environment of Schizosaccharomyces pombe (Petersen and Russell 2016). We have not yet tested this

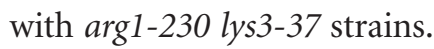

EMM2

\begin{tabular}{lcr} 
Reagent & Quantity (for 1 L) & Final concentrati \\
\hline Ammonium chloride & $5 \mathrm{~g}$ & $93.5 \mathrm{~mm}$ \\
Potassium hydrogen & $3 \mathrm{~g}$ & $14.7 \mathrm{~mm}$ \\
$\quad$ phthalate & & $15.5 \mathrm{mM}$ \\
$\mathrm{Na}_{2} \mathrm{HPO}_{4}$ & $2.2 \mathrm{~g}$ & $111 \mathrm{mM}$ \\
Glucose $_{\text {Salt stock }(50 \times)}$ & $20 \mathrm{~g}$ & $1 \times$ \\
Vitamins $(1000 \times)$ & $20 \mathrm{~mL}$ & $1 \times$ \\
Minerals $(10,000 \times)$ & $1 \mathrm{~mL}$ & $1 \times$ \\
$\mathrm{H}_{2} \mathrm{O}$ & $0.1 \mathrm{~mL}$ &
\end{tabular}

Prepare $1 \mathrm{~L}$ of EMM2 by combining the reagents above. To prepare solid medium, include agar $(20 \mathrm{~g} / \mathrm{L})$. Sterilize by autoclaving at $10 \mathrm{psi}$ for $10 \mathrm{~min}$ (for liquid medium) or $15 \mathrm{~min}$ (for solid medium). (For liquid medium, low pressure and a short cycle is essential to avoid caramelization of glucose and breakdown of vitamins and minerals. For live cell imaging, filter-sterilized medium has lower background fluorescence than autoclaved medium. Use a $0.22-\mu \mathrm{m}$ pore size for filtration.) Store at $4^{\circ} \mathrm{C}$. If desired, add $12 \mu \mathrm{M}$ thiamine $(364 \mu \mathrm{L}$ of a filter-sterilized stock solution of $10 \mathrm{mg} /$ $\mathrm{mL}$ on $\mathrm{H}_{2} \mathrm{O}$ ) after autoclaving to fully repress expression from $n m t 1$-derived promoters (Maundrell 1990).

EMM2-LowAmm

Reagent Quantity (for 1 L) Final concentration

Ammonium chloride
Potassium hydrogen phthalate
$\mathrm{Na}_{2} \mathrm{HPO}_{4}$
Glucose
Salt stock $(50 \times)<\mathrm{R}>$
Vitamins $(1000 \times)<\mathrm{R}>$
Minerals $(10,000 \times)<\mathrm{R}>$
$\mathrm{H}_{2} \mathrm{O}$

$\begin{array}{rr}0.32 \mathrm{~g} & 6 \mathrm{mM} \\ 3 \mathrm{~g} & 14.7 \mathrm{mM} \\ 2.2 \mathrm{~g} & 15.5 \mathrm{~mm} \\ 20 \mathrm{~g} & 111 \mathrm{~mm} \\ 20 \mathrm{~mL} & 1 \times \\ 1 \mathrm{~mL} & 1 \times \\ 0.1 \mathrm{~mL} & 1 \times\end{array}$

Prepare $1 \mathrm{~L}$ of EMM2-LowAmm by combining the reagents above. Sterilize by autoclaving at 10 psi for $10 \mathrm{~min}$. (Low pressure and a short cycle is essential to avoid caramelization of glucose and breakdown of vitamins and minerals.) Store at $4^{\circ} \mathrm{C}$.

Minerals $(10,000 \times)$

Reagent Quantity (for 1 L)

Final concentration

\begin{tabular}{|c|c|c|}
\hline Boric acid & $5 \mathrm{~g}$ & $80.9 \mathrm{~mm}$ \\
\hline $\mathrm{MnSO}_{4}$ & $4 \mathrm{~g}$ & $23.7 \mathrm{~mm}$ \\
\hline $\mathrm{ZnSO}_{4} \cdot 7 \mathrm{H}_{2} \mathrm{O}$ & $4 \mathrm{~g}$ & $13.9 \mathrm{~mm}$ \\
\hline $\mathrm{FeCl}_{2} \cdot 6 \mathrm{H}_{2} \mathrm{O}$ & $2 \mathrm{~g}$ & $7.40 \mathrm{~mm}$ \\
\hline Molybdic acid & $0.4 \mathrm{~g}$ & $2.47 \mathrm{~mm}$ \\
\hline $\mathrm{KI}$ & $1 \mathrm{~g}$ & $6.02 \mathrm{~mm}$ \\
\hline $\mathrm{CuSO}_{4} \cdot 5 \mathrm{H}_{2} \mathrm{O}$ & $0.4 \mathrm{~g}$ & $1.60 \mathrm{~mm}$ \\
\hline Citric acid & $10 \mathrm{~g}$ & $47.6 \mathrm{~mm}$ \\
\hline
\end{tabular}


A. Koch et al.

Salt Stock $(50 \times)$

Reagent

$\mathrm{MgCl}_{2} \cdot 6 \mathrm{H}_{2} \mathrm{O}$

$\mathrm{CaCl}_{2} \cdot 2 \mathrm{H}_{2} \mathrm{O}$

$\mathrm{KCl}$

$\mathrm{Na}_{2} \mathrm{SO}_{4}$

Store at $4^{\circ} \mathrm{C}$.

\section{SILAC Amino Acids}

Dissolve amino acid powder in high-purity, deionized $\mathrm{H}_{2} \mathrm{O}$ (i.e., Milli-Q) to make a $100 \times$ solution. After ensuring the amino acid has dissolved, filter the solution through a 0.22 $\mu \mathrm{m}$ filter. Store at $4^{\circ} \mathrm{C}$.

Vitamins $(1000 \times)$

Reagent

Quantity (for 1 L)

Pantothenic acid

Nicotinic acid

Inositol

Biotin

Store at $4^{\circ} \mathrm{C}$.

Yeast Extract with Supplements (YES)

Reagent

Amount to add (1 L)

Glucose

Yeast extract

$30 \mathrm{~g}$

Adenine

Uracil

Histidine

$1 \mathrm{~g}$

$10 \mathrm{~g}$

$10 \mathrm{~g}$

$10 \mathrm{mg}$
Final concentration

$$
\begin{array}{r}
0.26 \mathrm{M} \\
4.99 \mathrm{mM} \\
0.67 \mathrm{M} \\
14.1 \mathrm{~mm}
\end{array}
$$

$5 \mathrm{~g}$

$0.2 \mathrm{~g}$

$0.2 \mathrm{~g}$

$0.2 \mathrm{~g}$

Final concentration

Leucine

Lysine

$0.2 \mathrm{~g}$

$0.2 \mathrm{~g}$

Agar (for solid medium only)

$20 \mathrm{~g}$

$\mathrm{H}_{2} \mathrm{O}$

to $1 \mathrm{~L}$

Prepare $1 \mathrm{~L}$ of YES by combining the reagents listed above. Sterilize by autoclaving at $10 \mathrm{psi}$ for $15 \mathrm{~min}$. Store at $4^{\circ} \mathrm{C}$. (Note that the yeast contains sufficient thiamine to repress $n m t 1$ promoters.)

\section{ACKNOWLEDGMENTS}

Our work is supported by funding from the Juniorprofessoren-Programm of the BW-Stiftung and SFB 766 of the German Research Council (DFG) to B.M., and by a Wellcome Trust grant (094517) to K.E.S., A.K., and S.H. received funding from SFB 446 of the German Research Council (DFG) and the Max Planck Society. W.E.B. was supported by a Cancer Research UK PhD Studentship (C20060/ A10789). The Wellcome Trust Centre for Cell Biology is supported by core funding from the Wellcome Trust (092076).

\section{REFERENCES}

Bicho CC, de Lima Alves F, Chen ZA, Rappsilber J, Sawin KE. 2010. A genetic engineering solution to the "arginine conversion problem" in stable isotope labeling by amino acids in cell culture (SILAC). Mol Cell Proteomics 9: 1567-1577. 
Borek WE, Zou J, Rappsilber J, Sawing KE. 2015. Deletion of genes encoding arginase improves use of "heavy" isotope-labeled arginine for mass spectrometry in fission yeast. PLoS One 10: e0129548.

Carpy A, Patel A, Tay YD, Hagan IM, Maček B. 2015. Nicl inactivation enables stable isotope labeling with 13C615N4-arginine in Schizosaccharomyces pombe. Mol Cell Proteomics 14: 243-250.

Carpy A, Koch A, Bicho CC, Borek WE, Hauf S, Sawin KE, Maček B. 2016. Stable isotope labeling by amino acids in cell culture (SILAC)-based quantitative proteomics and phosphoproteomics in fission yeast. Cold Spring Harb Protoc doi: 10.1101/pdb.prot091686.

Fantes PA, Creanor J. 1984. Canavanine resistance and the mechanism of arginine uptake in the fission yeast Schizosaccharomyces pombe. J Gen Microbiol 130: 3265-3273.
Grallert A, Hagan IM. 2016. Large-scale immunoprecipitation from fission yeast cell extracts. Cold Spring Harb Protoc doi: 10.1101/pdb .prot091595.

Hagan IM. 2016. Immunofluorescence microscopy of Schizosaccharomyces pombe using chemical fixation. Cold Spring Harb Protoc doi: 10.1101/ pdb.prot091017.

Maundrell K. 1990. nmt1 of fission yeast. A highly transcribed gene completely repressed by thiamine. J Biol Chem 265: 10857-10864.

Murray JM, Watson AT, Carr AM. 2016. Colony polymerase chain reaction with Schizosaccharomyces pombe. Cold Spring Harb Protoc doi: 10.1101/ pdb.prot090993.

Petersen J, Russell P. 2016. Growth and the environment of Schizosaccharomyces pombe. Cold Spring Harb Protoc doi: 10.1101/pdb.top079764. 


\section{Construction, Growth, and Harvesting of Fission Yeast Stable Isotope Labeling by Amino Acids in Cell Culture (SILAC) Strains}

André Koch, Claudia C. Bicho, Weronika E. Borek, Alejandro Carpy, Boris Macek, Silke Hauf and Kenneth E. Sawin

Cold Spring Harb Protoc; doi: 10.1101/pdb.prot091678

\begin{tabular}{|c|c|}
\hline $\begin{array}{r}\text { Email Alerting } \\
\text { Service }\end{array}$ & Receive free email alerts when new articles cite this article - click here. \\
\hline $\begin{array}{l}\text { Subject } \\
\text { Categories }\end{array}$ & $\begin{array}{l}\text { Browse articles on similar topics from Cold Spring Harbor Protocols. } \\
\text { Analysis of Protein Expression in Cultured Cells (57 articles) } \\
\text { Cell Biology, general (1382 articles) } \\
\text { Metabolic Labeling and Protein Modification (21 articles) } \\
\text { Preparation of Cellular and Subcellular Extracts (104 articles) } \\
\text { Proteins and Proteomics, general (575 articles) } \\
\text { Yeast (288 articles) } \\
\text { Yeast Genetics (135 articles) }\end{array}$ \\
\hline
\end{tabular}

